\title{
CAMBIASSU

\section{A blind legend: sonoridade inclusiva no processo de audiogame}

A bling legend: inclusive sonority in the processo f na audiogame

Jefferson Saylon Lima de Sousa

Mestrando do Programa de Pós-Graduação em Comunicação - Modalidade Profissional da Universidade Federal do Maranhão (PPGCOMPRO/UFMA). Pesquisador do Núcleo de Estudos em Estratégias da Comunicação - NEEC (CNPq/UFMA), E-mail: jefferson.saylonerdiscente.ufmabr.. 


\section{Carlos Benedito Alves da Silva Júnior}

Doutorando do Programa de Pós-Graduação Comunicação, Cultura e Amazônia da Universidade Federal do Pará (PPGCOM/UFPA). Professor Assistente do Departamento de Comunicação Social da UFMA e Pesquisador do Núcleo de Estudos em Estratégias da Comunicação - NEEC (CNPq/UFMA), e do Grupo de Pesquisa em Comunicação, Discurso, Linquagem e Memória na Amazônia (CNPq/UFPA). E-mail: carlos.alves@ufufmabr.

\section{Rosinete de Jesus Silva Ferreira}

Doutora em Psicologia Social pela Universidade Estadual do Rio de laneiro (UER]). Mestra em Comunicação Social pela Universidade Federal do Rio de laneiro (UER]). Professora Associada 1 da Universidade Federal do Maranhão. Coordenadora do Núcleo de Estudos e Estratégias na Comunicação - NEEC. Líder da linha Estratégias Audiovisuais na Comunicação - GPEAC. E-mail: rosineteferreira@ufufma.br. 


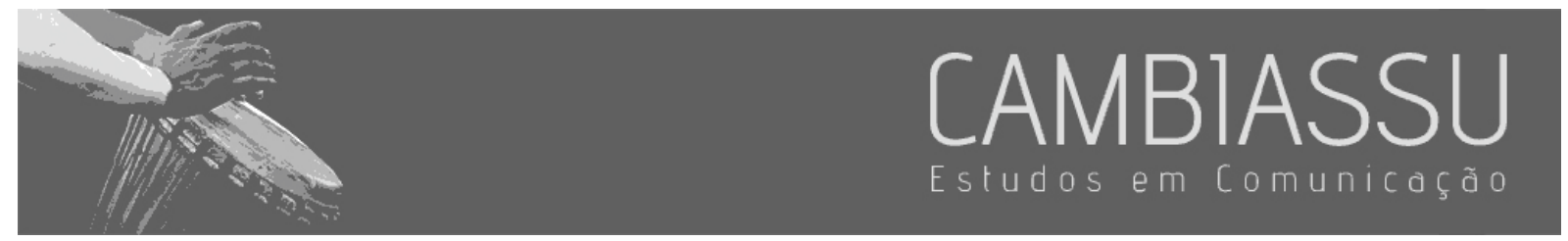

\section{Resumo}

A partir das noções de Game Sound e Topologia Sonora analisamos a sonorização do accessible game francês $A$ Blind Legend, que se trata de um audiogame mobile do gênero adventure. Discutindo sobre os conceitos de áudio interativo reativo e áudio interativo adaptativo observaremos como cada uma das três técnicas de sonorização inclusiva aplicadas neste tipo de jogo - Audio Quake, Serialization e Audio Icons/Audio Cues - se comportam dentro da narrativa consumida através do áudio binaural. A proposta é compreender como se desenvolve a sonoridade em um jogo eletrônico 100\% sonoro a partir da ótica da imersão e da inclusão. Faz-se antes uma breve revisão histórica sobre o papel do som nos jogos eletrônicos.

Paldvras-chave: audiogame; game audio; a bling legend; sonorização inclusiva.

\section{Abstract}

From the notions of Game Sound and Sound Topology, we analyzed the sound of the French accessible game $A$ Blind Legend which is a mobile audiogame of the adventure genre. Discussing the concepts of reactive interactive audio and adaptative interactive audio we will observe how each of the three inclusive sound techniques applied in this type of game - Audio Quake, Serialization and Audio Icons/Audio Cues behave within of the narrative consumed through binaural audio. The proposal is to comprehend how the sonority is developed in a $100 \%$ sound electronic game from of the optical of the immersion and inclusion. Rather, a brief historical review of the role of the sound in electronic games is made.

Keywords: audiogame; game audio; a blind legend; inclusive audio. 


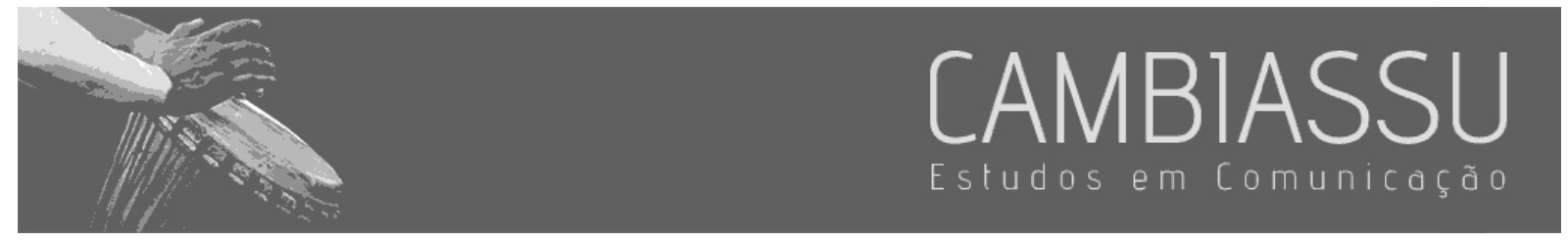

\section{Introdução}

A sonoridade de um jogo eletrônico é observada a partir de quatro aspectos: voz, ambientação sonora, efeitos sonoros e eventos musicais. A indústria, seus profissionais e entusiastas, denominam esse conjunto de elementos de Game Sound. Isso porque, diferente da maioria das outras mídias que fazem uso da linguagem audiovisual, o jogo eletrônico trabalha sua relação com o som a partir de construções e contextos não lineares. Rouse III (2005, p. 124) considera esta não linearidade como um dos mais importantes elementos dos games porque "[...] concede aos jogadores uma sensação de liberdade no mundo do jogo, permitindo aos jogadores ter experiências únicas, contar sua própria história"1.

A não linearidade, que pode se dar na narrativa (storytelling), nos resultados (multiple solutions), na ordem das ações (order) e na seleção de desafios (selection), relaciona-se com o Game Sound a partir do momento que cada um dos seus quatro elementos ajudam a compor o cenário sensível para as decisões do jogador; o que Collins (2008) veio a chamar de áudio interativo. A autora apresenta uma série de argumentos propostos por diversos pesquisadores das áreas de Tecnologia e Mídia. Estes conceituam os games enquanto mídia de narrativa interativa/ativa que envolvem atividades diegéticas, a partir de elementos visuais e sonoros, e extradiegéticas, a partir da jogabilidade e da experiência. Essa permuta entre ação e sensação é o desafio do jogo eletrônico. Tal premissa se intensifica quando se trabalha o jogo evidenciando apenas uma experiência ou elemento que seja comum entre muitos jogadores, como no caso pode ser a audição.

Nesse cenário, o audiogame constitui-se como interessante elemento de estudo, pois se vale tão somente do Game Sound para construir o espaço imersivo, que reúne jogo e jogador em uma homeostase de sentidos em que a audição assume o protagonismo, tornando-se a principal guia para o entendimento e vivenciamento da narrativa contada ou das ações aplicadas.

\footnotetext{
${ }^{1}$ Tradução nossa de: "[...] grant players a sense of freedom in the game-world, to let players have a unique playing experience, to tell their own story." (ROSE III, 2005, p. 124)
} 


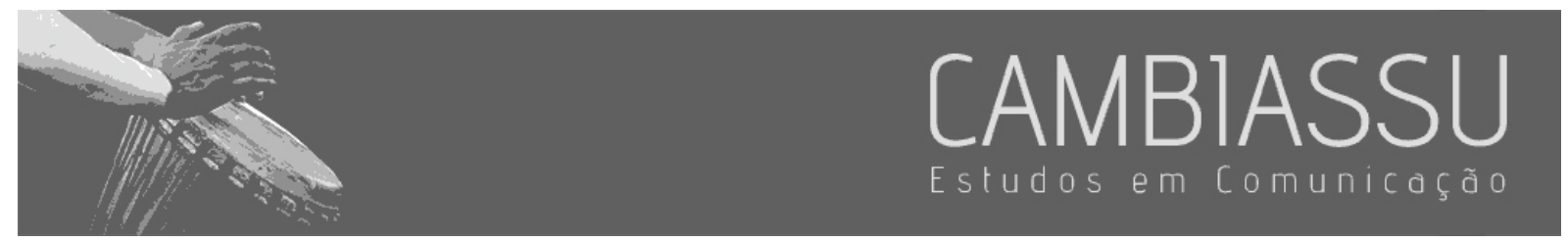

Não se pode esquecer que este debate abre espaço para tratar sobre ações inclusivas. O jogo eletrônico, diferente de outras formas de mídia, divide de maneira bem explícita o seu público a partir dos estímulos sensoriais disponíveis ao uso. O videogame, por contar também com o recurso imagético, em muitos momentos ignora o público deficiente visual (DV). Sem os recursos inclusivos, tais como a audiodescrição, o jogo - que depende da resposta de todos os estímulos - tem sua experiência incompleta diante de alguém que não pode ver o que acontece em cena, o que por sua vez afasta jogadores videntes daqueles não videntes por julgarem estes incapazes de se relacionarem com o ambiente de discussões sobre jogos.

De maneira orgânica, os audiogames acabam cumprindo esse papel ao construírem sua trama a partir e tão somente de estímulos sonoros, o que por sua vez constitui-se em um elemento inclusivo inerente ao jogo em suas ações e narrativas. Considerando isto, busca-se aqui discutir como a predominância de uma narrativa exclusivamente sonora é capaz de promover experiências de imersão e inclusão entre jogadores videntes e não videntes do jogo de acessibilidade móvel: $A$ Blind Legend².

Discutindo à luz da conceituação das quatro camadas do Game Sound propõe-se analisar como o audiogame em questão apresenta-se como modelo para a produção e assimilação do que chamaremos de sonoridade inclusiva, em que a sonorização do jogo o torna atrativo para os dois grupos de jogadores. Investiga-se isso correlacionando o conceito de Topologia Sonora (SHUM, 2008) e o conceito de Paisagem Sonora (SCHAFER, 2001). Assim, caracterizar-se-á suas rotinas de elaboração do ambiente sonoro a partir das classificações de áudio interativo-reativo e áudio interativoadaptativo proposta por Collins (2008).

Antes, contudo, será feito um breve levantamento histórico sobre os audiogames tendo como ponto de partida o próprio surgimento da linguagem sonora nesta mídia, já que os primeiros sons em

2 Disponivel em: http://www.ablindlegend.com/en/home-2/. Acesso em: 05 fev. 2019. 


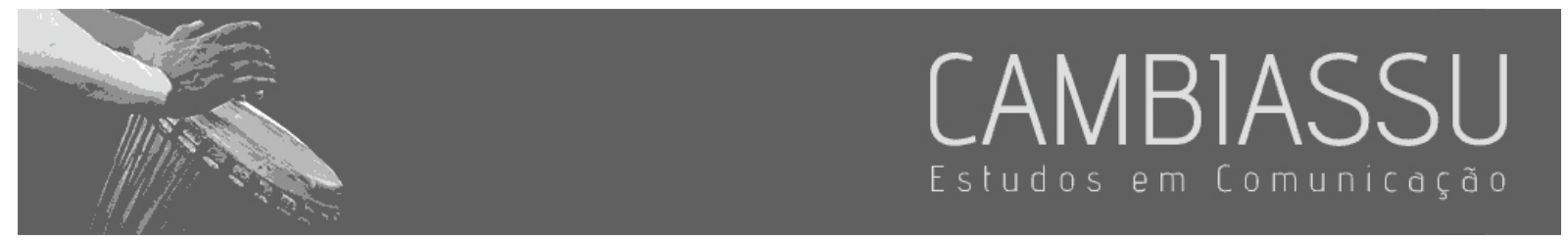

jogos eletrônicos não foram decisões estéticas, e sim o resultado direto da capacidade tecnológica limitada da época.

\section{Histórico do game sounde o videogame}

É preciso ter cuidado quando se trata sobre o áudio em jogos eletrônicos. As muitas terminologias acabam mais por confundir que ajudar quem investiga esse campo de atuação. $O$ audiogame diz respeito a um gênero de jogo eletrônico em que sua produção/composição dá prioridade ao som para estimular ações e contar a narrativa. Pode ou não haver ausência de visual para uma imersão completa no que é proposto a ser jogado.

Game Sound diz respeito a tudo o que está vinculado aos elementos sonoros no universo do jogo eletrônico. Discutindo sobre o Game Sound e sobre a sonoridade dos jogos eletrônicos e sua história, encontramos uma área de pesquisa interdisciplinar que dialoga não só com a Programação, mas com a Música, a Sonoplastia e a Comunicação Inclusiva.

Conforme apresenta em seu livro Game Sound: an introduction of History, Theory and Practice of Video Game Music and Sound Design (2008), Karen Collins afirma que as primeiras aplicações de som nos jogos eletrônicos sofreram influência de outros jogos populares na primeira metade do século XX: os caça-níqueis, pinballs e pachinkos ${ }^{3}$. Esses jogos mecânicos analógicos já possuíam recursos sonoros primários que ajudavam a criar uma ambientação de bem-estar e domínio do jogador sobre os acontecimentos presentes na máquina. Conforme Collins (2008, p. 8): "Mais importante é que o som foi um fator-chave na geração do sentimento de sucesso, já que os efeitos sonoros eram frequentemente usados para vitórias ou perto das vitórias, para criar a ilusão de vencer"4.

\footnotetext{
${ }^{3}$ Nome dado às máquinas japonesa de jogos de azar que reúnem elementos dos caça-níqueis e pinball. Predecessor do fliperama (Nota dos autores)

4 Tradução nossa de: "More important is that sound was a key fator in generating the feeling of success, as sound effects were often used for wins or near wins, to create the illusion of winning." (COLLINS, 2008, p. 8)
} 


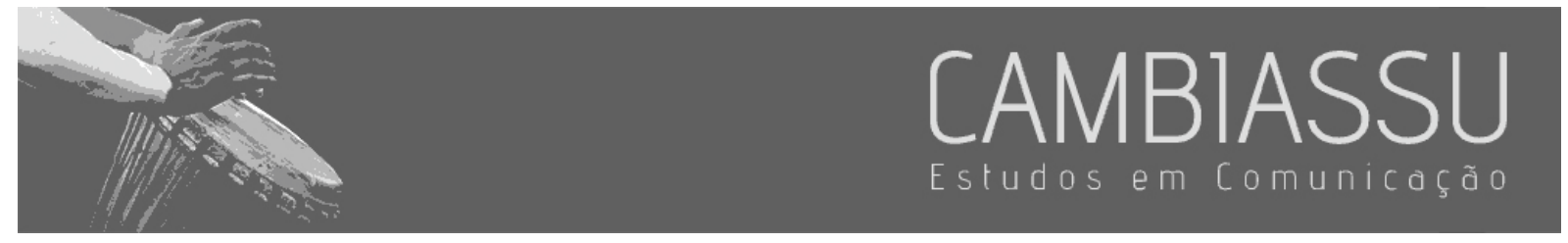

Os primeiros jogos eletrônicos datam do início dos anos 1960 e, em suas primeiras experimentações, os desenvolvedores preocuparam-se inicialmente com a construção de uma mecânica que fosse agradável ao usuário e com visual minimamente consumível. Elementos sonoros - inspirados nos caça-níqueis e pinballs - só seriam inseridos nos títulos comercializados a partir da década seguinte com a tecnologia do 8-bit Audio, que nada mais é que a organização através da digitalização de ondas em organizações ternárias do código binários ( 0 e 1) em oito possibilidades distintas.

Pong (1974), da desenvolvedora Atari, é reconhecido como o primeiro game do mundo a contar com elementos sonoros em seus dados. Inspirado no tênis de mesa, o jogo reproduz um tom em 8-bit sempre que a "bola" toca nas "raquetes" dispostas nas duas extremidades verticais da tela preta. Outro tom é executado quando a bola toca nas "paredes" laterais na parte superior e inferior da tela. Um terceiro tom é reproduzido sempre que a "raquete" não alcança a "bola" e o ponto é marcado.

Depois desse jogo, a presença de sons em games tornou-se uma obsessão da indústria, que disputou firmemente por inovações tecnológicas tanto nos gráficos quanto no áudio. Entre 1979 e 1980, a japonesa Atari lançou Asteroids e Space Invaders, respectivamente, que inseriram o conceito de música contínua nos jogos eletrônicos. Compostas de duas notas, as trilhas preenchiam o "vazio acústico" das duas tramas ambientadas em aventuras cósmicas. Esse foi o ponto de partida para outra desenvolvedora japonesa, a Konami, lançar, em 1981, Frogger, o jogo introdutório do conceito de dynamic music. Agora a trilha sonora possuía variações de intensidade e velocidade conforme os eventos do jogo se sucedem. Tal recurso permanece vivo nas produções de games e reverbera na multiplicidade de temas e eventos musicais compostos para um único título. Antes, entretanto, a Atari volta a inovar ao lançar Disc of Tron (1983) com onze gamesongs, além de música tema de "início de fase" e "game over". O jogo também é considerado o primeiro da indústria a ter sua sonoridade toda em som estéreo. 


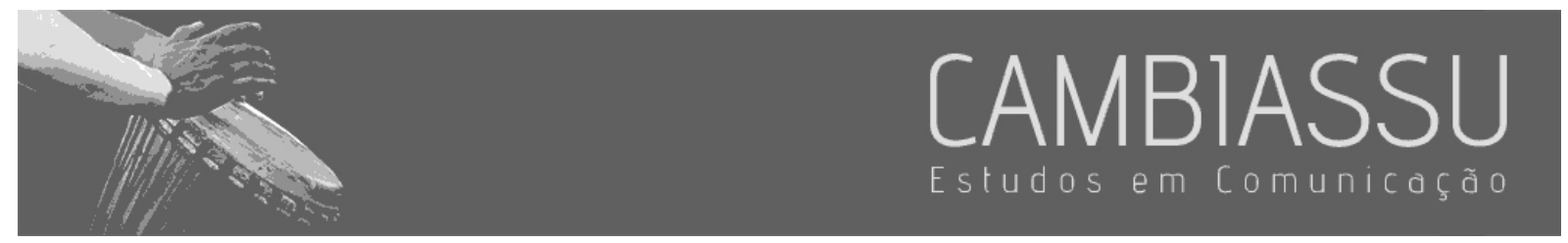

A mudança nesse cenário de aplicabilidade da técnica para a estética do som caminhou de forma pragmática entre o 16-bit, 32-bit, 64-bit e o Áudio Digital. O Game Sound consolidou suas bases e definiu que há diferentes formas de aplicação do áudio nesta mídia. Aqui entra em foco também o gênero audiogame, que se desenvolve paralelamente junto ao sucesso do primo conhecido (os videogames) embora com menos pompa.

Reconhecido como o primeiro audiogame, Touch Me (1974), da Atari, era um arcade game portátil similar ao design de um voltímetro, em que sua jogabilidade constituía-se em ouvir uma sequência sonora e reproduzi-la em seguida, com a ação de apertar os botões coloridos do console conforme as indicações dadas no display durante o momento de escuta. Essa experiência guiada a partir da sonoridade/musicalidade tornou-se símbolo dos primeiros movimentos envolvendo as narrativas sonoras nos jogos eletrônicos e ajudaram a construir o gênero, que passou a trabalhar com construções que tomam como premissa a rotina musical (Guitar Hero, em 2005), karaokê (SingStar, em 2004), dança (Just Dance, em 2009), além de elementos de acessibilidade (Papa Sangre, em 2010).

Para Shum (2008) o termo ajuda a definir um grupo maior de games que incluem sound games (jogos sonoros), music games (jogos musicais) e accessible games (jogos com acessibilidade). Em uma organização metodológica podemos classificá-los como gênero midiático e os demais como subgêneros. A ideia de formato estaria vinculada mais à proposta da narrativa ( hack ' $n$ ' slash, Strategy RPG, FPS, MMO etc.).

Quadro 01. Classificação Gênero e Subgêneros do Audiogame.

\begin{tabular}{|c|c|c|}
\hline GÊNERO & SUBGÊNERO & CARACTERÍSTICA \\
\hline \multirow{3}{*}{ AUDIOGAME } & SOUND GAME & \multirow{2}{*}{ AUDIOVISUAL } \\
\cline { 2 - 3 } & MUSIC GAME & \\
\cline { 2 - 3 } & ACCESSIBLE GAME & SONORO \\
\hline
\end{tabular}

Fonte: (AUTORES, 2021) 


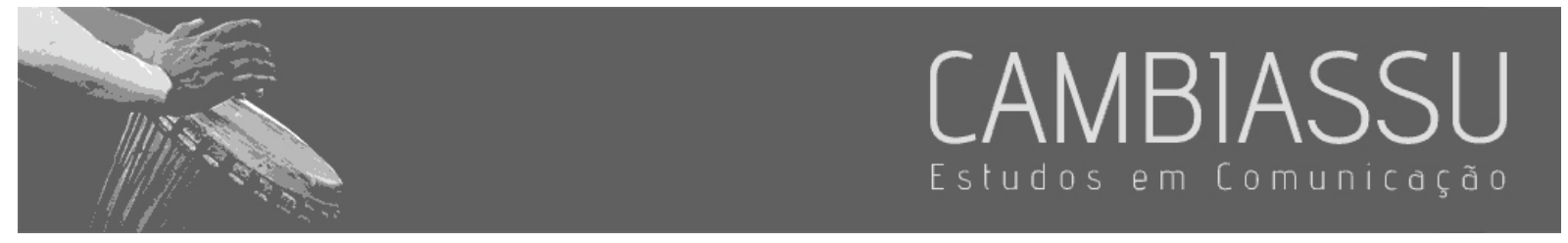

Importante destacar que nesta classificação somente os accessible games caracterizam-se como jogos $100 \%$ sonoros. Tais jogos possuem uma diferença crucial em relação aos demais por abdicar de um sentido humano para a promoção das ações e execução das narrativas.

Nos jogos $100 \%$ sonoros (sem interface gráfica), todas as referências espaciais são oferecidas ao jogador por intermédio dos sons. Por isso, na maioria das vezes, os ambientes sonoros costumam ser menos complexos do que em diversos jogos eletrônicos convencionais, com o objetivo de simplificar a jogabilidade. Nos jogos mais elaborados são utilizados recursos como gravações binaurais que reconstituem a tridimensionalidade da propagação sonora. (SHUM, 2008, p. 188-189).

Essa ausência da imagem promove-se como um elemento de inclusão para diversos grupos de pessoas - no caso em especial, os deficientes visuais - que no geral não poderiam fazer uso dos demais tipos de jogos por questões fisiológicas e/ou cognitivas.

Fazendo usos de recursos técnicos, estéticos e narrativos que destacam a audição como principal sentido aplicado no universo do jogo (experiência diegética) e por consequência a jogabilidade disponível (experiência extradiegética), os accessible games colocam em voga uma imersão a partir de fatores inclusivos: uma sonoridade inclusiva. O termo aqui proposto diz respeito ao objetivo primário do Game Sound, que é harmonizar as diferentes camadas do áudio - voz, ambientação sonora, efeitos sonoros e eventos musicais - a fim de "[...] cumprir funções diversas como chamar a atenção do jogador para determinar aspectos do jogo, criar emoções, representar e identificar tempo e espaço, personagens, etc." (MORAES, 2017, p. 33). Essa harmonização - que nada mais é que uma sonorização em lote e programada em linguagem computacional - tem como solução promover identificação com o jogo, sendo assim imersão, e quando isso acontece diante de uma proposta de reunir jogadores independente de diferenças há também a inclusão. 


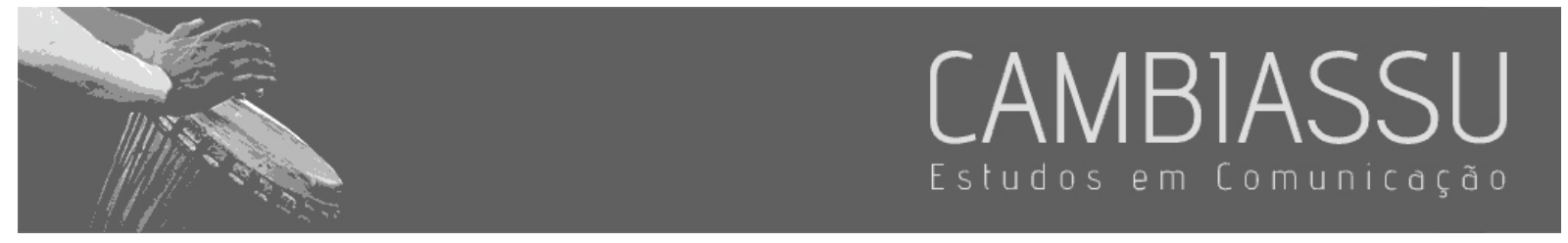

Com efeito, essa sonoridade inclusiva existe a partir de uma representação do ambiente sonoro apresentado e contém diversas paisagens sonoras reunidas. Essas muitas paisagens sonoras também podem ser classificadas como topologia sonora, conceito apresentado por Shum (2008, p. 161) como:

"[...] um desdobramento capaz de representar novas formas de jogabilidade e de navegação em jogos eletrônicos, a partir da possibilidade da localização, pelo jogador, de seu posicionamento no mapa do jogo com auxílio de músicas e de outros sons".

Simulando um ambiente sonoro amplo, diversificado, $A$ Blind Legend será analisado a seguir considerando a noção de topologia sonora acima citada, a fim de identificar como a imersão obtida através do áudio produzido e reproduzido direto nos fones de ouvido permite que tanto videntes e não videntes desfrutem de uma narrativa estimulante sem precisar da visão como guia principal no processo de absorver informações.

\section{Áudio dinâmico e sonoridade inclusiva em A Blind Legend}

Você é um antigo lorde e cavaleiro agora sem o prestígio do passado, que caminha por suas terras ao lado de esposa e filha. Em meio a uma balburdia de vozes na rua do comércio, você escuta o latido de cães misturado ao crepitar das forjas e fornos quentes de ferreiros e padeiros. A algazarra se intensifica com risos, gargalhadas, conversas e passos. O vento sopra entre as vielas e de repente carrega consigo o soar dos sinos da igreja ao centro da vila. Esses sinos não são um chamado às orações. São um aviso. Daí em diante cavalos e carruagens saem em disparada pelas ruas raptando mulheres. Sua esposa é uma das vítimas. Você tenta resgatá-la a todo custo, mas não consegue parar os malfeitores e ainda é atingido nos olhos e fica cego. 


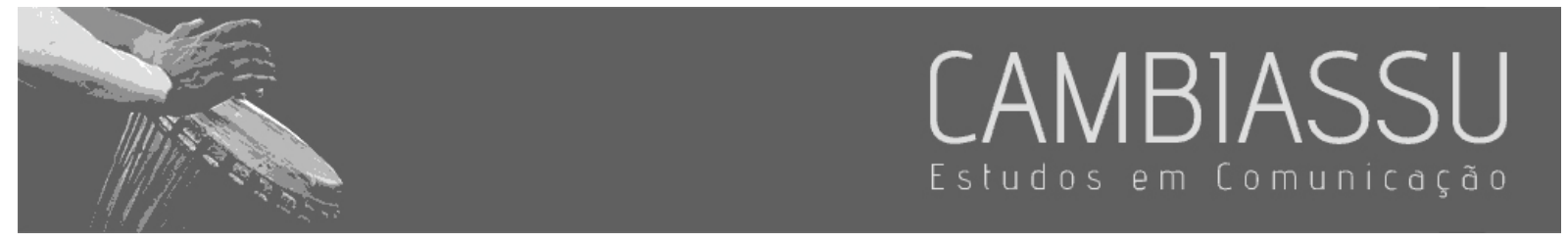

Esse é o plot presente na cutscene de abertura do jogo $A$ Blind Legend, produzido pela empresa francesa DOWiNO e que recria um mundo com referência às narrativas medievais europeias romantizadas a partir da renderização de diversas paisagens sonoras. Um adventure game com mecânica hack'n slash ${ }^{5}, A$ Blind Legend propõe-nos um jogo em que, para alcançar nosso objetivo (resgatar a esposa), devemos conduzir o protagonista Edward Blake por uma jornada cheia de bandidos, feras selvagens, monstros e ambientes hostis. Sua única auxiliar, além dos sentidos naturais que Ihe restaram, é a intrépida Louise Blake, sua amada filha, que o guia por aquele mundo com comandos de voz tal qual um GPS, uma bússola (ALVES, 2018).

Enquanto um accessible game sonoro, ele faz com que o jogador não vidente não se sinta prejudicado diante da forma como a narrativa é construída, apresentada e desenvolvida, pois tudo acontece por meio do som; e faz com que o jogador vidente experimente a sensação de se orientar tão somente pelo som como sentido de movimentação e cognição do espaço ao redor. Tal orientação pelo som reverberado no ambiente (e pertencente a ele) promove uma construtibilidade do espaço que delimita e contextualiza-o enquanto local de atuação dos elementos presentes em cena; uma transformação do som em referenciais imagéticos.

O som é, em essência, um espaço liso, um conjunto contínuo, que só adquire significado quando transformado em unidades discretas, descontínuas, ou seja, quando esse som ganha um enquadramento que lhe permite ter significado. Assim, o processo de percepção do som implica na tradução do em imagens, ou seja, na sua "discretização", no estabelecimento de um enquadramento que Ihe dê significado. (FERREIRA, 2010, p. 276).

Em A Blind Legend, encontramos aplicações da sonoridade inclusiva como elemento narrativo imagético. Há então uma sintaxe sonora (FERREIRA, 2010), que por sua vez corresponde em uma

\footnotetext{
${ }_{5}^{5}$ Pode ser traduzido como "corte e massacra". É um tipo de jogo que enfatiza o combate corpo-a-corpo. Originalmente descreve um estilo de jogabilidade em jogos de mesa de Role Playing Games (RPG) de papel e caneta, adaptado para os tipos MUDS, MMORPGs, e jogos eletrônicos em geral.
} 


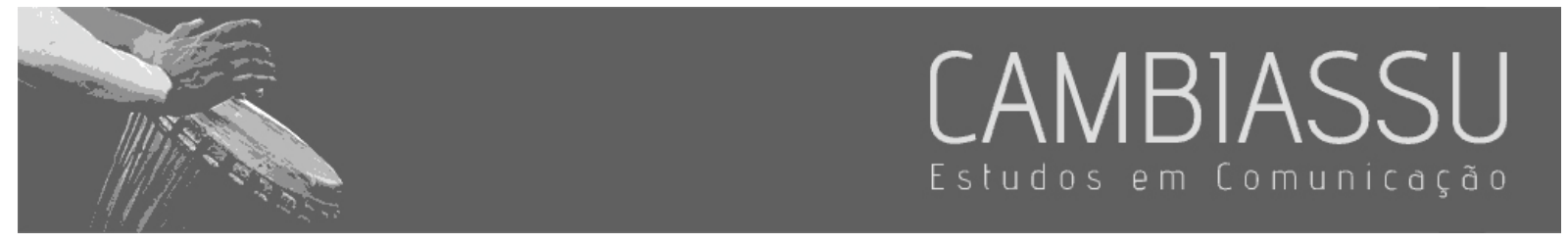

ação sinestésica em que o som se traduz em imagem no objetivo de construir uma espacialidade na qual ocorre essa narrativa. Tal espacialidade se desdobra em múltiplas paisagens sonoras dispostas a cada cena e fase do jogo em uma construção de contextos e relevos.

Para Schafer (2001), um elemento presente naquilo que ele chama de paisagem sonora é fator inicial e primordial para entendermos o comportamento e o estado de espírito de tudo o que vive: os sons fundamentais. Tais elementos "[...] não precisam ser ouvidos conscientemente; eles são entreouvidos, mas não podem ser examinados, já que se tornam hábitos auditivos, a despeito deles mesmo" (SCHAFER, 2001, p. 26).

A máxima retrata um gatilho para a imersão através do som. Isso porque no contexto primário "[...] a ideia de imersão está ligada ao sentimento de fazer parte do ambiente" (NETTO et. al, 2002, p. 10-11 apud COSTA, 2019, p. 45) e por tal, interagir com os sons fundamentais de uma paisagem sonora é se relacionar com eles percebendo-os como parte de um todo. Qualquer mudança em um som fundamental altera a imersão predefinida e é um convite à uma nova espacialidade.

Em contrapartida, para contextos de inclusão, esse sentimento não pode ser encarado de mesma forma. Pessoas que nasceram cegas detém uma audição acusmática que não precisa de um referencial imagético primário para compreender/apreender a paisagem sonora em que se encontram. Assim sendo, para elas a ideia de fazer parte do ambiente é bem mais sensitiva, sinestésica, pois mesmo esses sons fundamentais detêm valores que comunicam informações físicas e abstratas a respeito do lugar onde se está e como este reage.

Para Shum (2008), a sonoplastia é a responsável por responder questões técnicas dentro da narrativa a partir de cada paisagem sonora existente e suas particularidades. Ele encara a diversidade de paisagens sonoras de um jogo como um único conjunto denominado topologia sonora. 


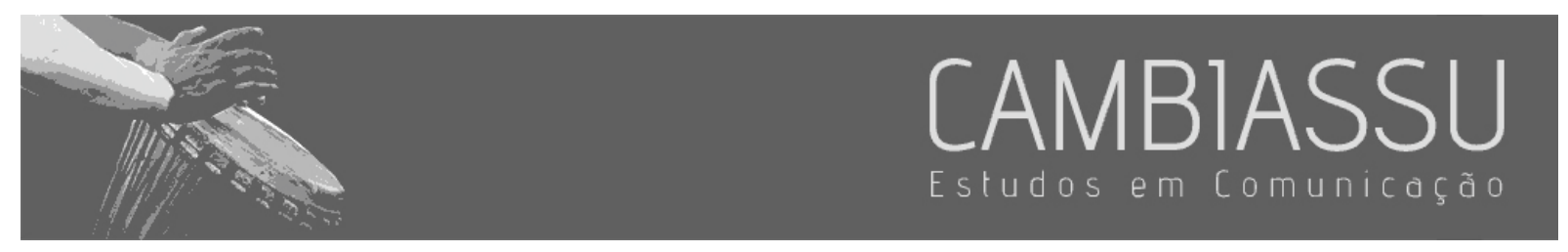

[...] a topologia sonora de um game, em sentido amplo, é o conjunto das paisagens sonoras deste game e suas correlações com o ambiente, os espaços e os comportamentos do jogo, definidos em termos de possíveis ações diegéticas e/ou não-diegéticas da máquina e do jogador. (SHUM, 2008, p. 2).

A topologia sonora de um game requer atenção ao espaço de ações não-diegéticas do operador (jogador). Dado o caráter eminentemente inicial das ações de configuração, bem como dos incrementos de recursos (saúde, vidas, dinheiro, poderes, armas, munição, fases, níveis etc.), é recomendável que o som atue como feedback para o jogador de que a ação realizada foi bem-sucedida ou que seu status no jogo foi modificado. (SHUM, 2008, p. 67).

A partir do áudio dinâmico em 3D, $A$ Blind Legend se sustenta na representação de uma espacialidade por meio da construção de imagens sonoras que referenciam também a tateabilidade/textura e o movimento (FERREIRA, 2010). A aplicação dessa relação do áudio dinâmico com a topologia sonora de um game é apresentada por Collins (2008) em conceito denominado áudio interativo. A autora, no entanto, faz questão de deixar claro que o termo é usado sempre acompanhado de complemento (reativo e adaptativo) e explicita que um diz respeito aos eventos sonoros de natureza extradiegética e de natureza diegética, respectivamente. Entendendo esses conceitos em $A$ Bind Legend, temos:

Quadro 02. O Áudio Dinâmico Interativo Reativo/Adaptativo em A Blind Legend

\section{REATIVO}




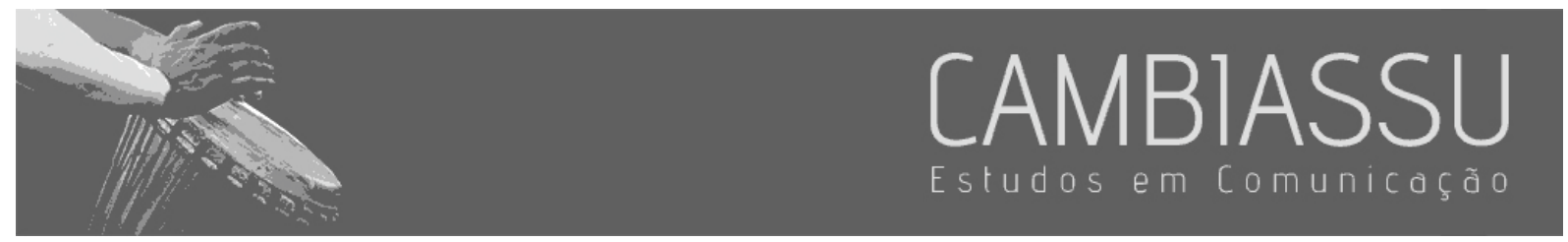

Refere-se aos eventos sonoros que reagem às ações do jogador, ou seja, ao contexto extradiegético da narrativa. Cada elemento sonoro do jogo passa a se comportar de acordo com o que foi executado ou não executado pelo jogador. Em $A$ Blind Legend isso pode ser percebido quando "sacamos" a espada. Quando esta ação é executada a reação é a reprodução de um efeito sonoro simulando o desembainhar da arma. Ao deslizar os dedos diante do display escuro do smartphone na busca por atacar os inimigos, ouvimos o som da arma sendo brandida no ar, colidindo com outras espadas, retalhando ou decepando membros etc. Encontramos aqui exemplos de áudio interativo reativo.

\section{ADAPTATIVO}

Refere-se aos eventos sonoros que reagem às mudanças no jogo, ou seja, ao contexto diegético da narrativa. Cada elemento sonoro do jogo comporta-se de forma pré-definida ao que já está estabelecido em sua programação. Em $A$ Blind Legend isso pode ser percebido quando acessamos diferentes cenários. A cada nova espacialidade acionada no jogo somos convidados a experimentar a multidão da cidade com suas infinitas possibilidades de sons a partir do trinômio distância-alturaprofundidade. Quando estamos no cenário da mata selvagem somos apresentados aos sons do farfalhar das folhas, grunhido de animais e som do vento. Quando há a mudança de clima - para uma chuva, por exemplo - parte dessa ambientação é alterada e o que se ouve já não é percebido pelo ouvido com a mesma periodicidade e/ou intensidade. A acústica também é alterada quando se está em ambiente fechado, como é o caso das cenas dentro da caverna atrás da cachoeira (na segunda fase do jogo) ou quando o personagem cai da ponte e entra no rio se afogando (terceira fase) quando somos inseridos numa sonoridade subaquática. Encontramos aqui exemplos de áudio interativo adaptativo.

Fonte: (AUTORES, 2021) 


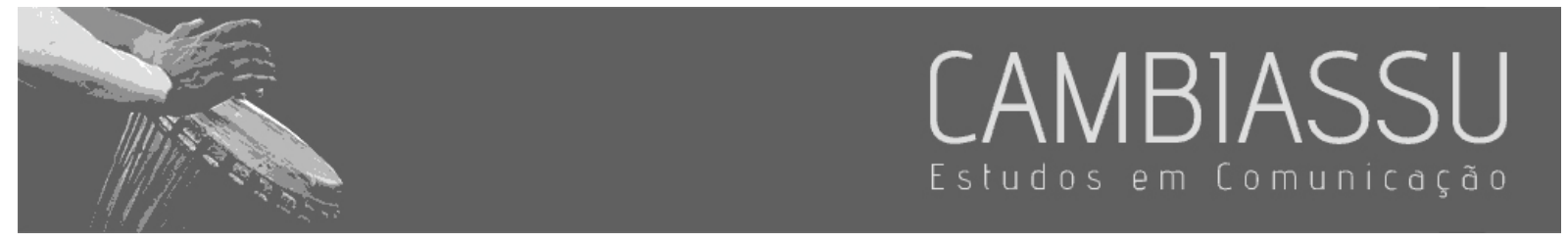

Todavia, essas percepções auditivas em um accessible game requerem condições de produção que ajudem a construir essa espacialidade tridimensional imersiva e inclusiva. Destaca-se então três técnicas de sonorização que são imprescindiveis para a realização de um jogo sonoro acessível: Audio Quake, Serialization e Audio Ícons/Audio Cues (ARAUJO et al, 2017, p. 5):

Quadro 03. Técnicas de sonorização para um jogo sonoro acessível (ARAUJO et al, 2017, p. 5)

\section{AUDIO QUAKE}

Simula um radar e usa metáforas sonoras para indicar a posição de objetos móveis e fixos. Por exemplo, sons são emitidos da posição do inimigo para que este seja localizado. Eles ganham intensidade (ou alarmes) de acordo com a aproximação do adversário. Alguns autores indicam o Audio Quake como a primeira técnica de adaptação sonora produzida.

\section{SERIALIZATION}

Esta técnica trata das prioridades do jogo na reprodução do som. Distintos níveis de informação (por exemplo, inimigos, obstáculos, etc.) têm diferentes níveis de prioridade em relação ao tempo de sonorização. Portanto, os sons correspondentes devem ser serializados de acordo com essa prioridade, o que indica sua importância para a compreensão do jogo. Nesse sentido, vários paradigmas de prioridade podem ser usados nesta técnica a depender do que o programador e o roteirista desejam para aquele momento do jogo e também para as reações do jogador.

\section{AUDIO ICONS/AUDIO CUES}




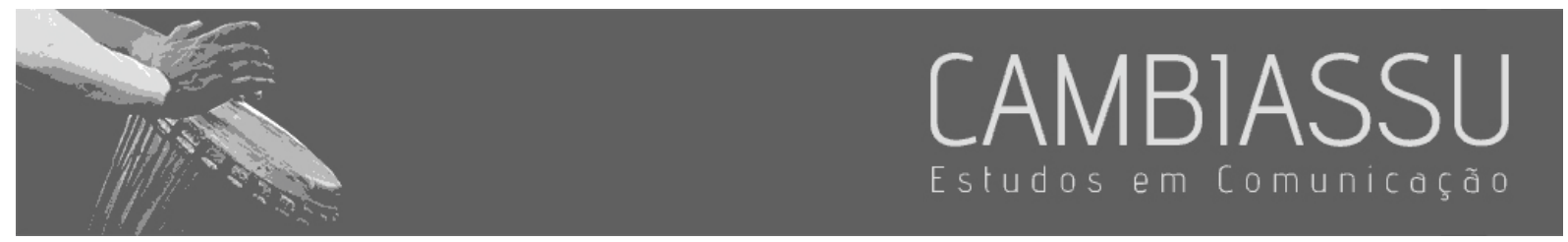

Esta técnica propõe a adição de efeitos sonoros ao jogo com pistas para promover a identificação de objetos ou descrever ações no jogo. Por exemplo, o jogo realiza um som de colisão, e em seguida é executado um áudio indicando que há uma parede em frente ao avatar do jogador e que ele não pode seguir. São sinais não diagéticos que auxiliam na condução da partida e reconhecimento do cenário. A inserção de narração se encaixa nesse item.

Fonte: (AUTORES, 2021)

Em $A$ Blind Legend esses recursos técnicos são facilmente identificados durante a experiência do jogo e se distribuem de maneira bastante perceptiva entre os elementos do Game Sound (voz, ambiência sonora, efeitos sonoros e eventos musicais). A seguir, estabelece-se a relação entre as técnicas de sonorização de jogos acessíveis e as quatro camadas do Game Soundem A Blind Legend. Considerando que a própria desenvolvedora do jogo (DOWiNO) informa que ele foi produzido com áudio binaural, classificamos aqui a técnica 3D Audio Icon/Audio Cues, que é um desdobramento dos Audio Icons/Audio Cues.

\section{Relação $01 \rightarrow$ Audio Quake a partir da Voz}

Funcionando como o Audio Quake do jogo, o NPC Louise Blake (filha) funciona como uma bússola ao jogador, guiando-o através da voz com comandos direcionais sempre que tocamos na tela à procura destas informações. A proposta é auxiliar o jogador a construir seu caminho de forma objetiva sem se afastar demais das rotas ou tropeçar em armadilhas ou bloqueios naturais do cenário. Entre os comandos, algumas expressões como: 


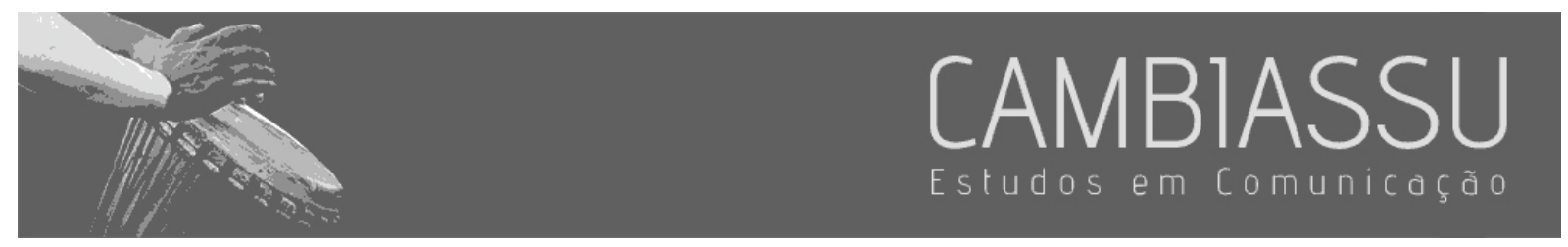

"Over here!" // "Turn around!" // "Turn right/left!" // "Alright!" // "This way, father!" // "Let's go!" // "Straight ahead!" |/ "Most to the right/left!" |/ "Behind you!" |/ "It's behind you" |/ "I'm behind you!" // "Over to the right/left!" // "Carefull!" // "Now, get close to me!" // "Go on!" // "Faster!" // "Enough!" // "Jump!".

\section{Relação $02 \rightarrow$ Serialization a partir de Efeitos Sonoros e Eventos Musicais}

Para este recurso técnico, $A$ Blind Legend reserva uma infinidade de elementos inseridos ao longo de sua narrativa. Contudo alguns são bem marcantes para o jogador quando da determinação dos eventos-chave da trama como transição de cutscenes e início/fim de momentos de ação. Efeitos Sonoros que se destacam nessa categoria são:

1) SFX Corneta // SFX Tambor // SFX Cavalos // SFX Armas // SFX Gritos.

2) SFX Batimento Cardíaco de Edward Blake.

Sempre quando o primeiro grupo de efeitos sonoros se repete de forma sequencial, a compreensão do jogador deve ser de imediato sobre o início de uma cena de ação. Seja para fugir, se esconder ou lutar, quando estes efeitos estão reunidos significa que uma tropa inimiga se aproxima e você tem um tempo limitado para cumprir a meta prevista para a cena (esconder-se atrás de uma cachoeira, correr para a mata, sacar a espada etc.). É importante destacar que respeitando a sequência sonora relatada acima, o jogo cria um termômetro auditivo de tensão/adrenalina onde SFX Corneta indica que ainda estão longe e SFX Gritos indica que seu avatar foi localizado.

O segundo grupo de efeitos sonoros (SFX Batimento Cardíaco) é bem representativo, pois informa de imediato ao jogador se seu personagem está bem ou não. Após as ações do primeiro grupo de efeitos sonoros, o jogo nos permite ouvir os batimentos cardíacos de Edward Blake, que se 


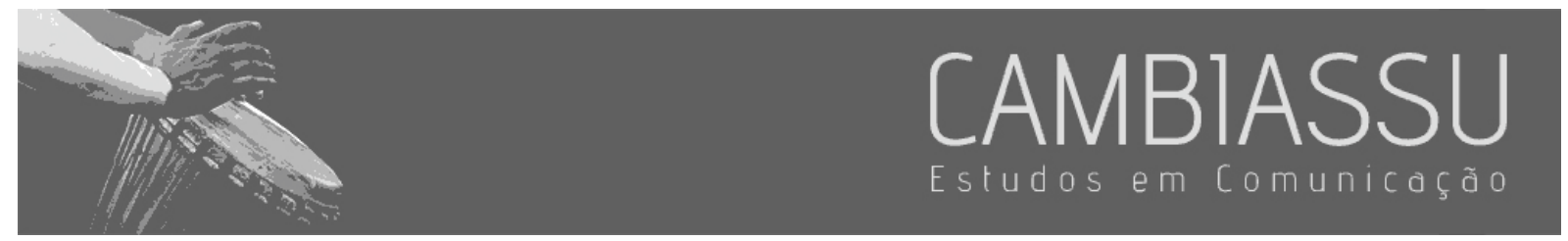

intensificam conforme cada um dos efeitos sonoros anteriores é reproduzido. Os batimentos chegam ao ápice quando em batalha. Além da respiração ofegante (um efeito sonoro secundário à ação da luta), ouve-se claramente os batimentos do coração de Blake sofrendo alterações como aceleração, arritmia, até chegar à parada cardíaca, que ocorre diante da derrota/morte dele. É interessante ressaltar que quanto mais aceleradas e disformes, o SFX Batimento Cardíaco significa muitos danos tomados por Edward Blake. Neste ponto, é categórico afirmar que esse efeito sonoro faz a vez da Health Bardo personagem, visto que não temos uma referência visual para isso.

Deve-se considerar também que o jogo tem pouquíssimos eventos musicais durante sua execução. Todos eles são diegéticos e indicativos de localização, pois estão diretamente ligados às vilas com seus festivais ou comitivas acompanhadas de percussionistas. $\mathrm{O}$ enquadramento desses eventos musicais com a técnica Serialization é feito a partir da observação de que eles indicam mudança na prioridade do jogador. Diferente dos efeitos sonoros que vem para indicar ação, em $A$ Blind Legend os eventos musicais referem-se à introdução de diálogos ou início/fim de fases (como é o caso da trilha de tensão no game over).

\section{Relação $03 \rightarrow 3 D$ Audio Icons/Audio Cues a partir da Ambiência Sonora}

Os sinais de áudio em 3D disponíveis em $A$ Blind Legend correspondem a mais da metade do jogo em si. Como sua narrativa é $100 \%$ sonora, tudo o que existe no mundo do jogo só é perceptível a partir do som. Desta maneira, todos os demais sons ouvidos no jogo relacionam-se com a espacialidade criada e intensificam a imersão através da simulação das texturas e intensidades do espaço. Entre os sons de maior relevância para este item temos:

\section{1) SFX Passos de Edward Blake;}




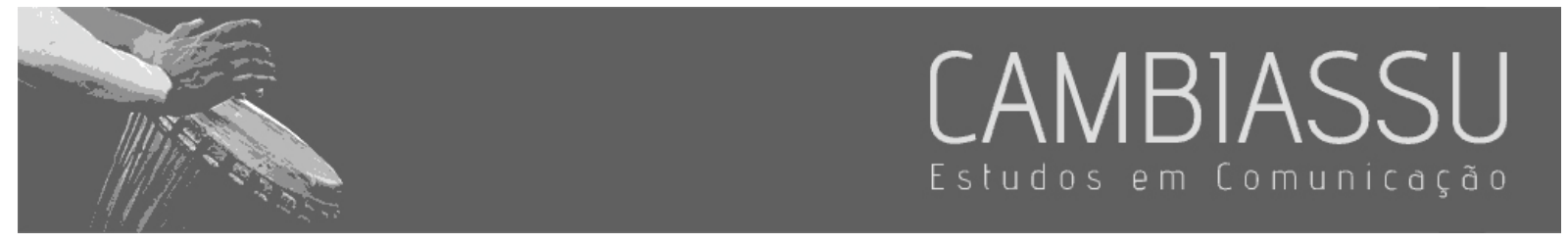

\section{2) SFX Vento // SFX Animais.}

De forma pragmática, o SFX Passos, além de indicar o movimento do protagonista (feito a partir do deslizar do dedo junto ao display do smartphone), nos ajuda a interpretar o ambiente ao redor através do som. A identificação de texturas do solo onde Blake pisa permite ao jogador compreender quando ele está na floresta (passos sobre grama e gravetos), na cidade (passos firmes sobre rocha, cascalho ou chão de terra), na praia (passos fofos e molhados), áreas com neve (passos fofos e silenciosos). Essa identificação multissensorial do tato por meio do som é algo de extremo valor para a narrativa, mas muito mais para o usuário, que faz a imersão sem precisar ver onde pisa.

Já o segundo grupo de elementos sonoros presentes no ambiente ajudam a identificar noções como altura, distância e tempo. Para altura, o SFX Vento assume papel fundamental quando estamos na montanha, por exemplo, onde conforme mais alto subimos, mais forte ele sopra e nos impede de absorver os comandos de Louise. Na praia, ele nos impede de definir com precisão onde está a fonte sonora dos rugidos (no caso um monstro), pois altera o movimento das águas e do próprio som do monstro. No caso dos SFX Animais, o ambiente em que estamos conta sempre com fauna distinta. Se na cidade: cães, cavalos, ovelhas etc. Se na mata: lobos, corujas e outras bestas como monstros. Os animais também podem indicar a passagem de tempo, pois quanto mais cedo é, mais forte é o canto dos pássaros. Quanto mais tarde é (no caso durante a noite), o uivo dos lobos e o pio das corujas ambientam a paisagem sonora indicando a sensação de penumbra.

\section{Considerações finais}

Sabendo que em $A$ Blind Legend os elementos sonoros estão reunidos em uma sonorização que dialoga com dispositivos de saída (headphones e earphones) tornando muito individual a relação entre o jogador e a narrativa, em que encontramos uma imersão híbrida a partir de sentidos como 


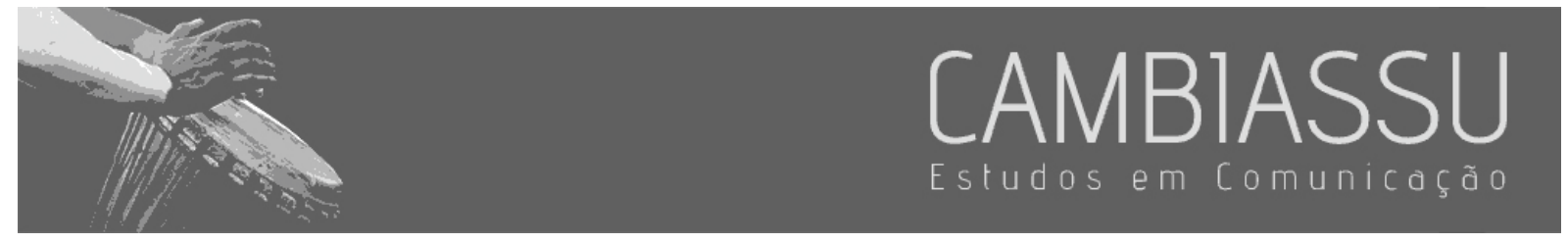

audição e tato se intensificando graças ao fone de ouvido, que permite ao usuário se conectar com a narrativa (COSTA, 2019).

Isso só e possível, no entanto, devido às técnicas de captação e edição que recorrem a microfones e/ou plug-ins de áudio binaural (FERREIRA et al, 2018). Guiar-se pelo mundo de fantasia de $A$ Blind Legend só é possível com a presença dos periféricos de escuta que permitem ao usuário se localizar no espaço narrativo por meio das indicações sonoras do ambiente de simulação do real, e pela interação que existe entre as personagens.

As técnicas de sonorização aqui descritas comprovam que há sim métodos eficazes de se construir um ambiente $100 \%$ sonoro que apresente desafios interativos para videntes e não videntes. A inclusão e a imersão provenientes do jogo eletrônico $A$ Blind Legend podem ser caracterizadas a partir de diferentes aspectos e técnicas aplicadas quanto à capacidade de adaptação dos sons no processo de composição do espaço interativo, onde jogador e jogo se comunicam em uma mobilização de troca de experiências para finalizar uma meta, um objetivo.

Dessa forma, conclui-se que a sonoridade inclusiva é uma realidade possível já que oferece oportunidades criativas aos desenvolvedores de jogos ao mesmo tempo em que promove acessibilidade de muitos grupos ao universo lúdico dos jogos (neste caso em especial os DVs). Contudo, é preciso que se tenha em mãos as ferramentas específicas para aplicação das técnicas propostas - sendo algumas delas relacionadas como a binauralidade - a fim de explorar as narrativas sonoras não só em audiogames, mas em outros produtos sonoros atuais.

\section{Referências}

A BLIND LEGEND. DOWiNO, 2019. Disponível em: http://www.ablindlegend.com/en/home-2/.

ALVES, João. Estratégias para uma narrativa imersiva: proposta de análise sobre os recursos sonoros de A Blind Legend. In: CONGRESSO BRASILEIRO DE CIÊNCIAS DA COMUNICAÇÃO, 41., Joinville. Anais [...]. Joinville:[s.n], 2018. Disponível em: http://portalintercom.org.br/anais/nacional2018/resumos/R13-0451-1.pdf. Acesso em: 11 abr. 2019. 


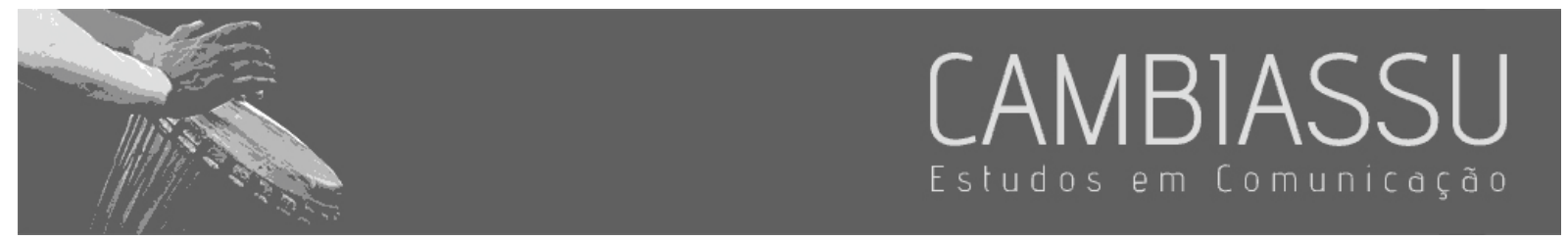

ARAUJO, Maria; FAÇANHA, Agebson; DARIN, Ticiane; SÁNCHEZ, Jaime; ANDRADE, Rossana; VIANA, Windson. Mobile Audio Games Accessibility Evaluation for User Who Are Blind. In: ANTONA, Margherita; STEPHANIDIS, Constantine. Universal Access in Human-Computer Interaction: designing novel interactions - Part II. Vancouver: Springer, 2017.

COLLINS, Karen. Game sound: an introduction to the history, theory, and practice of video game music and sound design. Cambridge: The MIT Press, 2008.

COSTA, Bruna Rafaella Almeida da. Audio 3D e Corpo Plugado: uma análise sobre Imersão Sonora na série Stranger Things. 2019. 123 f. Dissertação (Mestrado em Comunicação) - Programa de Pós-Graduação em Comunicação. Universidade Federal de Goiás, Goiânia, 2019.

FERREIRA, Gisele Sayeg Nunes. Imagens em som: o som que se faz ver da radiodifusão comunitária na web. In. FERRARETO, Luiz Artur; KLÖCKNER, Luciano. E o Rádio? Novos horizontes midiáticos. Porto Alegre: EDIPUCRS, 2010.

FERREIRA, Rosinete; SILVA JÚNIOR, Carlos Benedito Alves da; SOUSA, Jefferson Saylon Lima. Áudio em Três Dimensões: experimento e gravação de áudio binaural. In: MOURA, Flávia de Almeida et al. Produção de sentidos e tecnologia: estudos contemporâneos em comunicação. São Luís, EDUFMA, 2018.

MORAES, Tharcízio Vaz. Composição Musical no Audio Game Breu: os desafios e processos de um jogo inclusivo. 2017. 152 f. Dissertação (Mestrado em Música) - Programa de Pós-Graduação Música. Universidade Federal da Bahia, Salvador, 2017.

ROUSE, Richard. Game design: theory \& practice. Plano-Texas: Worldware Publishing Inc, 2005.

SCHAFER, Raymond Murray. A afinação do mundo. São Paulo: Editora UNESP, 2001. SHUM, Lawrence Rocha. Topologia(s) sonora(s) nos games. 2008. 243 f. Tese ( Doutorado em Comunicação e Semiótica) Pontifícia Universidade Católica de São Paulo, São Paulo, 2008. 